\title{
МЕТОДИЧЕСКИЕ ОСОБЕННОСТИ ИСПОЛЬЗОВАНИЯ РОЛЕВОЙ ИГРЫ ПРИ ИЗУЧЕНИИ АНГЛИЙСКОГО ЯЗЫКА НА НЕЯЗЫКОВЫХ ФАКУЛЬТЕТАХ УНИВЕРСИТЕТА
}

\section{METHODOLOGICAL FEATURES OF THE USE OF ROLE-PLAYING GAMES IN THE STUDY OF ENGLISH AT NON-LINGUISTIC FACULTIES OF THE UNIVERSITY}

\section{U. Ovezova \\ M.-N. Wagner}

Summary: The article defines the place of role play in the English language classes at a higher educational institution. Attention is focused on the study of the discipline "Foreign language" at non-linguistic faculties. Based on the results of the analysis of pedagogical literature, the interest of teachers in role play as an active method of teaching English was revealed. The article shows that the place of role play in practical classes is determined depending on the stage of education and language training of students. The principles of using role-playing games in improving lexical skills are highlighted; the effectiveness of their application in the process of teaching students to communicate in English has been proved.

Keywords: dialogue, game method, communication, lexical skills, minigame, preparatory work, role-playing game, communication.

\section{Введение}

$\mathrm{B}$ течение обучения в учреждении высшего образования студенты изучают иностранный язык. На неязыковых факультетах количество часов значительно меньше по сравнению с профильным обучением. Поэтому студентам сложнее овладевать навыками общения на иностранном языке. Как следствие, снижена мотивация студентов к коммуникации именно на английском языке. Действенным методом активизации общения на английском языке является ролевая игра на занятиях. Актуальность указанной проблемы обусловлена тем, что в ходе игры студенты легче усваивают фразы и клише, которые можно использовать в повседневном общении.

Анализ исследований и публикаций показывает интерес ученых к внедрению метода ролевой игры в процесс обучения. Так, U. Westrup, A. Planander [1] указывают, что введение метода окажется полезным при условии заинтересованности в нем студентов. R. Godwin-Jones [2] и Е.А. Рожнова [3] считают, что игра мотивирует к изучению иностранного языка. По мнению Г.М. Чудайкиной, Н.Ю. Логиновой, В.В. Костоваровой [4], учебная игра спо-

\author{
Овезова Умеда Акпаровна \\ К.и.н., дочент, Российский университет дружбы народов \\ umeda_77@mail.ru \\ Вагнер Моника-Наталия Лауренсовна \\ К.и.н., дочент, Российский университет дружбы народов
}

Аннотация: В статье определяется место ролевой игры на занятиях по английскому языку в высшем учебном заведении. Внимание сосредоточено на изучении дисциплины «Иностранный язык» на неязыковых факультетах. По результатам анализа педагогической литературы выявлен интерес педагогов к ролевой игре как активному методу обучения английскому языку. В статье показано, что место ролевой игры на практических занятиях определяется в зависимости от этапа обучения и языковой подготовки студентов. Выделены принципы применения ролевых игр при усовершенствовании лексических навыков; доказана эффективность их применения в процессе обучения студентов общению на английском языке.

Ключевые слова: диалог, игровой метод, коммуникация, лексические навыки, мини-игра, подготовительная работа, ролевая игра, общение.

собствует развитию самостоятельности, познавательной активности при изучении английского языка. Л.Ф. Шайхисламова [5] отмечает, что в процессе игры происходит взаимное обучение студентов вести разговор.

Л.В. Зенина с соавт. [6] признают ролевую игру эффективным учебным методом. Исследователи предлагают стимулировать собеседников к активному общению в процессе коммуникации, предлагают преподавателям моделировать речевые ситуации, приближенные к реальным событиям.

D. Rao, I. Stupans [7] советуют использовать коммуникативный метод во время аудиторного занятия. По их мнению, коммуникация эффективнее всего реализуется именно через игру. Ученые считают интервью и импровизацию простейшими, но и наиболее популярными формами ролевой игры, в ходе которой студенты запоминают сложные грамматические конструкции, учатся использовать их в общении.

J.R. McConville c соавт. [8] полагают, что проведение ролевой игры должно происходить в определенной по- 
следовательности. Преподаватель обязательно должен выбрать конкретную ситуацию, предоставить инструкции участникам по выполнению определенной роли.

Методисты предлагают использовать игры как при изучении грамматических форм английского языка, так и при усвоении лексики повседневного общения [9]. Важным также педагоги считают моделирование ситуаций, направленных на будущую профессиональную деятельность.

Исследователи [10] дают рекомендации относительно проведения ролевой игры на практическом занятии по английскому языку. Главными факторами для успешного внедрения метода ролевой игры в учебный процесс они считают простоту, скорость, приближенность к реальной ситуации; отдельное внимание уделяют предварительной подготовке к игре.

Цель статьи - определить основные принципы внедрения ролевых игр в процесс изучения английского языка.

Задачи статьи: выделить принципы применения ролевых игр при изучении студентами лексического материала, необходимого для дальнейшего общения на иностранном языке; установить, на каких этапах обучения введение ролевой игры будет наиболее действенным; раскрыть значение использования ролевых игр в процессе обучения студентов общению на английском языке.

\section{Изложение основного материала}

На протяжении изучения дисциплины «Иностранный язык» студенты постепенно совершенствуют навыки иноязычного общения. Поскольку содержание разговорных тем, предлагаемых программой по иностранному языку, знакомо студентам из школьного курса обучения, они теряют интерес к обсуждению определенных ситуаций. В связи с этим, следует обратить внимание студентов на те лексические единицы, которые им неизвестны, или которые они употребляют реже, а также на необычные идиомы.

Например, при изучении темы «Времена года. Погода» в процессе подготовительной работы к игре следует объяснить разницу между парами слов: weather/climate, shower/downpour, snowfall/snowstorm, sprinkling/ drizzling и т.п. Если фразы «downpour is coming», «it's pouring down rain», «l am wet through», «it's drizzling» воспринимаются студентами как обычные предложения, описывающие явления природы или состояние человека, то фразеологизмы кажутся забавными, необычными, непонятными: «indian sum mer», «it's raining cats and dogs», «fine weather for ducks». По желанию студенты могут найти в Интернете историю возникновения фразеологизма и сделать короткое сообщение на английском языке. Подчеркиваем, что следует принимать сообщения, найденные в проверенных источниках, научных статьях, словарях, пособиях. Достаточно одного-двух источников. Сообщение должно быть максимально коротким - примерно 0,5-0,7 страницы рукописной записи в тетради.

Далее студенты читают в парах диалоги, помещенные в учебнике. Преподавателю необходимо напомнить, что разговор людей обычно эмоционален, поэтому при чтении диалогов важно постараться интонационно передать эмоции собеседников: удивление, радость или недоверие и т.п. Если уровень подготовки студентов начальный, перевод диалогов осуществляет либо другая пара, которая не читала диалог вслух, либо та же пара, но участники меняются ролями и переводят не свои роли. Такое упражнение заставляет студентов обращать внимание на новые слова. Если уровень студентов промежуточный, диалоги не переводятся. Студенты должны изложить на английском языке содержание диалога. Чем короче диалог, тем короче высказывание - одна-две фразы. После чтения диалогов студенты проигрывают в ролях подобную ситуацию. Можно вспомнить аналогичную ситуацию из собственной жизни и обсудить ее, используя новые слова и фразы. К сожалению, студенты не всегда могут определить, какую именно ситуацию выбрать. Тогда преподаватель должен подсказать, о чем можно поговорить.

Например, при изучении темы «Основы разговора» студенты могут получить следующие задания:

1. Вы встречаете своего близкого друга на главной улице. Вы торопитесь. Скажите, что позвоните ему сегодня вечером.

2. Вам звонит ваш близкий друг. Спросите его, как $\mathrm{OH}$.

3. Вы встречаетесь со старым другом и разговариваете с ним о других друзьях.

4. Пригласите своего однокурсника посмотреть фильм, провести с вами вечер. Он/она согласится или откажется.

Студенты делятся на группы по два-три человека, выбирают одну из ситуаций. Обязательно обращается внимание студентов на формулы приветствия и прощания в повседневном и официальном общении. При необходимости можно сопровождать задания вспомогательными карточками с клише, которые служат для начала разговора. Это так называемые «оpening remarks», объединенные определенной темой: «Разговор о здоровье», «Разговор о погоде», «Официальные приветствия», «Неофициальные приветствия», «Комплименты».

Важно, чтобы студенты употребляли новые фразы 
сознательно. То есть использование предложений должно соответствовать выбранной ситуации. Собеседник должен соответственно реагировать на предложение, которое он услышал. Конечно, собеседники могут распространить список клише, их инициатива всегда одобряется преподавателем. Важно также обращать внимание на эмоциональную и интонационную окраску произносимых фраз.

При изучении темы «Внешний вид и характер» активизируются и обновляются предыдущие знания студентов. Сначала предлагается самостоятельно описать внешность любого лица: реального, вымышленного, фантастического и тому подобное. Обычно студенты ограничиваются описанием общих внешних признаков реального человека. Поэтому обращается внимание на цвет кожи, волос, форму носа, подбородок, телосложение человека.

Студенты могут получить дополнительное задание: описать внешность анимационного персонажа и реального лица, например, Микки Мауса и Тома Круза. Следует обратить внимание студентов, что анимационные персонажи обычно гротескные, поэтому и описание должно быть подходящее. Внешность данных действующих лиц обсуждается в парах. Для более слабых студентов это может быть диалог по принципу «вопрос-ответ», для более сильных - диалог-интервью: один играет роль выбранного персонажа, второй - корреспондент газеты или зритель. Обязательно обращается внимание на цвет одежды, волос, а также на характер выбранного героя.

Далее можно провести игру «Отгадай личность». Один студент описывает внешность и характер одногруппника, но не полностью. Другие должны отгадать, о ком рассказывает студент. Такая игра, как правило, вызывает интерес у собеседников, студенты вовлекаются в общение, начинают задавать дополнительные вопросы. Игра будет интереснее, если студенты постараются употреблять как можно больше синонимов, прилагательных при описании человека.

При изучении темы «Дом. Квартира» студенты предварительно знакомятся с новыми лексическими единицами, с названиями жилья человека. Также они тренируются в употреблении грамматических структур в процессе расспроса об определенном доме.

Поскольку рассказ о собственной квартире, комнате или доме не очень интересен студентам, можно провести игру «Мой воображаемый дом». Студенты могут принести на занятия изображение жилища человека. Изображение (фото, рисунок) может быть историческим, реальным, фантастическим и прочее. Студенты распределяются на малые группы по два-три человека и расспрашивают друг друга о представленном жилье. «Хозя- ин» дома рассказывает о своем замке, пещере, коттедже, а «гости» расспрашивают, есть ли в доме мебель, как она расположена, и так далее.

Следует отметить, что в зависимости от выбранного вида жилья разными будут наименования мебели, посуды. Поэтому студентам необходимо предварительно составить в тетради мини-словарик, в который записываются слова, отражающие выбранную эпоху. Естественно, что в процессе игры могут возникать вопросы относительно непонятных предметов домашнего обихода. В этом случае «хозяин» дома должен дать толкование предмета на английском языке. Подчеркиваем, что объяснения должны быть приготовлены заранее. Студенты могут ссылаться на толковые словари английского языка. Самостоятельный поиск значения выбранных слов помогает прочнее запомнить новые лексические единицы. Расспрашивая о расположении мебели, студенты параллельно повторяют особенности употребления предлогов в английском языке.

Изучая тему «Город», особое внимание следует обратить на городские виды транспорта, на дорожные знаки. На практическом занятии можно провести в игру «Правила дорожного движения». Студентам предъявляются дорожные знаки, и они должны ответить на английском, какой это знак и где он может быть расположен. Другой вариант игры: выбирается студент-ведущий, который расспрашивает одногруппников о дорожных знаках. Если ведущий неверно задает вопрос или пропускает указанный знак, выбирается другой ведущий.

Для тренировки и усвоения направлений движения в английском языке используется карта-схема проезда определенного города, допустим, Лондона. Студенты делятся на пары, выбирают определенное место на карте, но не сообщают друг другу об этом. Цель игры - с помощью расспросов найти друг друга и встретиться в городе, удаленном от обоих «пешеходов».

Другой вариант игры - экскурсия по городу. Студенты могут принести на занятия собственные карты какоголибо города и предложить себя в роли «экскурсовода». «Экскурсанты», по желанию студентов, могут потеряться на улице, задержаться в музее и тому подобное. Основная цель игры - говорить правильно, без ошибок, употреблять соответствующую лексику по теме.

Таким образом, результаты исследования показали, что проведение ролевой игры на занятиях по английскому языку требует значительной подготовительной работы. Именно на этапе подготовительной работы студенты учатся видеть разницу в употреблении синонимичных лексических единиц, повторяют особенности структурирования английского предложения. В течение усвоения новых лексем студенты учатся синтезировать приобре- 
тенные знания, использовать их на занятиях в учебных ситуациях.

При этом эффективность проводимой работы зависит от комплексного использования ряда дидактических принципов. Так, при изучении незнакомых, необычных лексических единиц применяется принцип новизны. В процессе поиска и обработки информации, в обращении к специальным словарям используются принципы научности, самостоятельности и систематизации. Действенным является принцип наглядности при демонстрировании фотографий, рисунков, использовании карточек, таблиц. Принцип активности проявляется в желании студентов самостоятельно искать новую информацию, а также фотографии, рисунки, карты и тому подобное, и делиться этим с одногруппниками. Принцип сознательности помогает студентам использовать клише, идиомы, новые лексические единицы в зависимости от выбранной ситуации.

\section{Зак^ючение}

В заключении исследования можно сделать следующие выводы.

Комплексное использование принципов, систематичность и последовательность усвоения нового учеб- ного материала способствует повышению интереса студентов к учебному предмету «Иностранный язык».

Проведение ролевой игры возможно при условии подготовительного этапа. Спонтанная игра не может происходить по той причине, что студенты могут не обладать необходимым словарным запасом. Таким образом, необходимо изучение лексических единиц и грамматических структур по определенной теме. Необходимо прочтение и даже заучивание наизусть диалогов-образцов, потому что структурное построение предложений английского и русского языка существенно отличаются. Когда студенты обладают определенными знаниями, им интереснее включаться в игру, и, как следствие, занятие по иностранному языку становится более интересным.

Необходимо сопровождать задания вспомогательными карточками с идиомами или рисунками, схемами, таблицами и тому подобное. Демонстрация различных видов наглядности помогает студентам активнее включаться в игру. Некоторые игровые элементы, мини-игры являются достаточно эффективными на подготовительном этапе обучения. Но наиболее действенным введение ролевой игры в процесс обучения является во время систематизации и обобщения знаний по определенной теме, то есть на завершающем этапе.

\section{ЛИТЕРАТУРА}

1. Westrup U., Planander A. Role-play as a pedagogical method to prepare students for practice: The students' voice// Högre utbildning. 2013. Vol. 3(3). pp. 199-210.

2. Godwin-Jones R. Games in language learning: Opportunities and challenges// Language Learning \& Technology. 2014. Vol. 18(2). pp. 9-19.

3. Рожнова Е.А., Симакова С.М. Ролевая игра как одна из форм интерактивного обучения иностранному языку в техническом вузе// Филологические науки. Вопросы теории и практики. Тамбов: Грамота, 2014. № 6 (36): в 2-х ч. Ч. І. С. 152-155.

4. Чудайкина Г.М., Логинова Н.Ю., Костоварова В.В. Ролевые игры в обучении иностранным языкам: теория и практика // Вестник Ассоциации вузов туризма и сервиса. Т. 11. 2017. № 4. С. 82-92.

5. Шайхисламова Л.Ф. Ролевые игры на основе информационно-коммуникационных технологий в обучении диалогической речи студентов неязыковых вузов // Филологические науки. Вопросы теории и практики. 2015. № 2-1 (54). С. 201-204.

6. Зенина Л.В., Жидкова 0.Н., Стрижова Е.В., Нисилевич А.Б., Герасименко Т.Л. Опыт использования ролевых игр в процессе обучения иностранному языку // Интернет-журнал «НАУКОВЕДЕНИЕ» 2014. № 6 http://naukovedenie.ru/PDF/179PVN614.pdf

7. Rao D. , Stupans I. Exploring the potential of role play in higher education: development of a typology and teacher guidelines// Innovations in Education and Teaching International. 2012. Vol. 49(4). pp. 427-436.

8. McConville J.R., Rauch S., Helgegren I., Kain J.-H. Using role-playing games to broaden engineering education// International Journal of Sustainability in Higher Education. 2017. Vol. 18 (4). pp. 594-607.

9. Ma T. The Application of Role-Playing Teaching Method in College English Teaching for Adult Education// 8th International Conference on Management, Education and Information (MEICl). 2018. Vol. 163. pp. 327-330.

10. Escudeiro P., Vaz De Carvalho C. Game-based language learning// International Journal of Information and Education Technology. 2013. Vol. 3. pp. $643-647$.

(c) Овезова Умеда Акпаровна (umeda_77@mail.ru), Вагнер Моника-Наталия Лауренсовна.

Журнал «Современная наука: актуальные проблемы теории и практики» 